\title{
Uma vocação para durar: estratégias discursivas e agências imperiais nos anos 1950
}

A vocation to last: discursive strategies and imperial agencies in the 1950s

\section{Carla Susana Alem Abrantes}

\section{(2) OpenEdition \\ 1 Journals}

Edição electrónica

URL: http://journals.openedition.org/aa/1435

DOI: $10.4000 /$ aa. 1435

ISSN: 2357-738X

Editora

Programa de Pós-Graduação em Antropologia Social (UnB)

\section{Edição impressa}

Data de publição: 1 dezembro 2015

Paginação: 173-197

ISSN: 0102-4302

\section{Refêrencia eletrónica}

Carla Susana Alem Abrantes, «Uma vocação para durar: estratégias discursivas e agências imperiais nos anos 1950», Anuário Antropológico [Online], v.40 n.2 | 2015, posto online no dia 01 junho 2018, consultado o 28 abril 2021. URL: http://journals.openedition.org/aa/1435 ; DOI: https://doi.org/ 10.4000/aa. 1435

\section{(c) (i) (9)}

Anuário Antropológico is licensed under a Creative Commons Atribuição-Uso Não-Comercial-Proibição de realização de Obras Derivadas 4.0 International. 


\title{
Uma vocação para durar: estratégias discursivas e agências imperiais nos anos 1950
}

\author{
Carla Susana Alem Abrantes
}

UNILAB

\section{Introduçáo}

O presente artigo delineia o saber colonial como uma prática discursiva, situando-o no contexto do ensino superior de Lisboa nos anos 1950. Tomaremos as dissertaçóes de licenciatura escritas sobre Angola por alunos da Escola Superior Colonial (ESC) - que em 1954 passou a se chamar Instituto Superior de Estudos Ultramarinos (ISEU) - como base empírica para uma reflexão sobre a mudança nas gramáticas e agências que tiveram lugar no contexto do colonialismo português tardio. ${ }^{1}$ Propõe-se uma descrição e análise antropológica desse material com o objetivo de localizar os modos como as sociedades africanas foram constituídas como objetos de conhecimento e de intervenção externa. Este artigo visa estabelecer bases para uma crítica ao saber produzido sobre sociedades não europeias e, assim, contribuir para a constituição de discursos autônomos pelos envolvidos no processo colonial.

Um dos primeiros a estabelecer essa perspectiva foi Talal Asad (1973), ao analisar a dialética desse saber e suas condiçôes práticas. Outros estudos contribuem para uma compreensão da heterogeneidade dos modos de (re)conhecimento do outro segundo agencialidades particulares e classificaçóes de cultura envolvidas por estratégias e modos de governar coloniais (Pels, 1997; Thomas, 1994). Textos e arquivos produzidos no contexto colonial, ao serem examinados à luz de métodos da antropologia, fazem emergir as agências, os conflitos e as condiçóes que tornaram viáveis a existência da prática colonial (Dirks, 1992; Stoler, 2009). Nesse sentido, a desconstrução de categorias de identificação é possível por meio de uma reconstituição dos relacionamentos históricos (Comaroff, 1997; Cooper \& Stoler, 1997) e do modo como intelectuais, instituições e administração local estiveram envolvidos na circulação, transmissão, reprodução e ressignificação de formas de conhecimento (Bastos, 2007).

O colonialismo português é conhecido, desde a década de 1980, pelo caráter fortemente ideológico de suas produçóes científicas (Gallo, 1988), tanto pelo vínculo estreito de intelectuais e instituiçôes nas esferas da economia e política 
(Castelo, 2012) como pelo pendor assimilacionista que marcou os modos de pensar e classificar a realidade (Conceição Neto, 1997; Fry, 2003; Pereira, 1987). A ideologia colonial portuguesa foi abordada por inúmeros estudos que mostraram representaçôes racializadas e procedimentos de propaganda nacional originados de instituiçóes de pesquisa e de ensino, em especial a partir do Estado Novo, em 1930 (Antunes \& Rodrigues, 2011; Matos, 2006; Paulo, 1992, 2001). Neste artigo, as dissertaçôes de licenciatura nos dão acesso a uma mudança de gramática e às práticas administrativas emergentes no contexto de reestruturação do regime colonial europeu que se seguiu à Segunda Guerra Mundial.

Parte-se da ideia do discurso como determinante dos modos de conhecimento do mundo e de relaçóes de poder entre os sujeitos que o produzem (Foucault, 2010), inspirando-nos, sobretudo, pelos estudos recentes desenvolvidos sobre documentos administrativos, seus regimes de fala e de silêncio sobre as sociedades e sua presença como peças da história no desenvolvimento de saberes administrativos (Souza Lima, 2002; Souza Lima \& Barreto Filho, 2005; Vianna, 2014). Populaçôes africanas e um Estado europeu foram classificados em situaçóes passíveis de serem descritas com base nos processos de organização de agências e agentes. De um colonialismo à margem, com um saber periférico (Leal, 2006), vemos emergir, no contexto português, redes articuladas por estratégias discursivas e bases institucionais que nos fornecem pontos de partida para uma recomposição de histórias coloniais diversas, mantendo, entretanto, visíveis as marcas nacionais de sua criação e vontade imperial.

À luz da descrição dos enunciados encontrados nas dissertaçôes e das relaçôes sociais que conferiram um lugar social a esses textos e seus autores, pretende-se identificar os pressupostos que condicionaram o saber colonial e o projetaram como uma vocação para durar. Por meio dessa análise, procura-se apontar caminhos que explicitem os efeitos de longa duração de certas estruturas de dominação e as razóes para ramificações profundas para certas continuidades nas sociedades pós-coloniais, tanto nas ex-metrópoles como nas ex-colônias (Elias, 1994, 2002; Mamdani, 1996).

$\mathrm{Na}$ primeira seção deste artigo, serão apresentadas as dissertaçóes de licenciatura resultantes da formação especializada criada a partir de 1949 no contexto da administração para as colônias africanas. Após essa caracterização dos textos sobre os quais versará este artigo, serão abordadas, na segunda seção, as estratégias discursivas e os padrôes classificatórios que informaram expectativas dirigidas às populaçôes locais e às agências do Estado colonial por parte dos especialistas em formação em Lisboa. $\mathrm{Na}$ terceira seção, apresentaremos o lugar social das dissertaçôes e seus autores, buscando uma compreensão das condiçóes 
de existência desses textos no cenário mais amplo e dinâmico dos anos 1950, em que discursos e estruturas imperiais se transformaram em meio às pressóes pela independência dos territórios colonizados e da emergência de novos espaços de diálogo e intervenção internacional.

\section{As dissertaçóes de licenciatura}

A partir dos anos 1950, os altos postos do governo português passaram a ser preenchidos por egressos da instituição de ensino vocacionada para a formação de quadros da administração, a ESC/ISEU. Até então, as posiçóes superiores, tais como "inspetores" e "governadores", eram preenchidas por profissionais com larga experiência na administração ultramarina e indicação do Ministério do Ultramar. Desde as primeiras décadas do século XX, a ESC havia se responsabilizado apenas pela preparação dos jovens que ocupariam as posiçôes de fronteira, em especial, as de "chefe de posto" e "administrador de circunscrição". A habilitação literária exigida para essas posiçóes poderia ser adquirida nas cadeiras oferecidas pela ESC no curso superior de administraçáo colonial de dois anos, cujo currículo foi definido em 1919 e reformulado e ampliado para quatro anos em 1926.

Nas cadeiras de "Colonização" e "Etnologia e Etnografia" oferecidas no curso básico, transmitiam-se ideias sobre "educação dos indígenas” e "justiça indígena" em conexão com a política do indigenato que estabeleceu, a partir de 1926, critérios para a condição especial de "indígena" dos territórios colonizados. Por "indígena” se definiam os africanos por uma distinçáo racial e cultural ("usos e costumes") por meio de um estatuto especial — o Estatuto do Indigenato —, que se constituiu como base para um conjunto de regulamentos em vigor a partir de 1928, tais como o Código do Trabalho Indígena. Nesses regulamentos coloniais, os africanos náo assimilados eram considerados sujeitos sem gozo de direitos políticos de cidadania, e, portanto em posição de tutela, cujos limites seriam definidos pelas autoridades coloniais, colocando grande parte da sociedade africana em posição de obrigatoriedade ao trabalho e às demandas da administração (Meneses, 2010; Penvenne, 1995). Assim, os conteúdos transmitidos nessas cadeiras do ensino básico correspondiam às responsabilidades esperadas pelas posiçóes de fronteira, entre as quais figurava o cotidiano de gestão dos "indígenas".

No contexto de reformulação do ensino de 1946, criou-se o ensino especializado de dois anos dirigido aos já versados nos conhecimentos coloniais e/ou experientes na gestão de territórios ultramarinos. ${ }^{2}$ Designada Curso de Altos Estudos Coloniais, também conhecida como licenciatura em ciências coloniais, essa formação complementar era entendida como um curso de aprofundamento a ser ofertado "à gente de cultura" por um corpo docente detentor de uma "cultura 
superior desinteressada" com o objetivo de desenvolver as "vocaçôes coloniais" ao alcance desses profissionais. As dissertaçôes eram o trabalho final de conclusão do curso, instrumento por meio do qual os estudos e pesquisas dos alunos eram avaliados por um júri escolar e tornados públicos - conforme previa a legislação da reforma da instituição pública. ${ }^{3}$ A conclusão e aprovação da dissertação diante de um júri garantia ao aluno o diploma de "licenciado" ou "colonialista" e facilitava-lhe o acesso às posiçóes mais altas do governo colonial.

Escritas a partir de 1949, as primeiras dissertaçôes não possuíam um formato padrão - heterogeneidade fértil para uma comparação entre os elementos que compuseram os seus roteiros narrativos. Contendo de 100 a 300 páginas, tais textos tiveram diferentes focos temáticos, tais como sociedades indígenas (antropologia), gestão das sociedades indígenas (política indígena), economia e história da expansão colonial, e estavam em sintonia com os objetos que interessavam aos professores orientadores. As temáticas traduziam uma gramática que foi renovada nos anos 1950, em diálogo com agências internacionais. Como veremos, muitos desses novos olhares antecipariam o fim do regime do indigenato, revogado em 1961.

Os resultados encontrados, como assim entendem seus autores, fazem vistas a um novo posicionamento da administração colonial e à necessidade de legitimar a presença de Portugal no contexto da mobilização internacional pós-Segunda Guerra Mundial. Assim, os estudos que se traduziriam em textos dissertativos compartilhavam do objetivo de contribuir para uma nova política colonial cuja proposta, no entanto, ainda considerava o "africano" ou "negro" como uma das partes mais relevantes do processo e sujeito aos desígnios dos interesses coloniais.

$\mathrm{Nas} 17$ dissertaçóes que versaram sobre política indígena e colonial em Angola, ou seja, que apresentaram os resultados de estudos sobre as populaçóes a quem se destinavam os projetos de intervenção estatais concebidos em Lisboa, 6 foram tomadas para uma análise mais detalhada durante a pesquisa (Castanheira, 1950; Mendes, 1958; Monteiro, 1959; Moura, 1955; Pereira Neto, 1960; Soares, 1961). ${ }^{4}$ Em tais narrativas, as populaçôes são a principal justificativa para a pesquisa, à exceção dos primeiros trabalhos $(1949,1950)$, que ainda se rendiam às motivações de uma escrita sobre "penetração" colonial e demandas de atividades econômicas em que a "falta de braços" se colocava como o principal "problema” a ser solucionado. A despeito das orientaçóes humanísticas que passaram a predominar nesses estudos, as populaçóes continuaram a ser vistas como a mão de obra por excelência dos projetos coloniais. Antigas imagens sobre o africano e sua não adaptação ao trabalho foram atualizadas ou readaptadas no sentido de se introduzirem perspectivas que renovassem a política colonial portuguesa de um cariz moderno. 
Os alunos inscritos nessa formação especializada valeram-se de métodos de análise e interpretação pautados pela antropologia biológica e cultural e por descrições de situaçóes recolhidas e relatadas em texto ao longo da sua experiência na administração colonial, em cargos de fronteira (postos administrativos ou circunscriçôes). Como "fatos", as caracterizaçóes dos alunos eram superficiais e com informações limitadas para que se identifiquem as situaçôes e condições em que foram coletadas/produzidas. Alguns trabalhos foram desenvolvidos por meio de pesquisa bibliográfica, o que passou a ser comum à medida que o curso acolheu estudantes cada vez mais jovens (até 25 anos) egressos da formaçáa básica sem experiência na administração colonial. Tanto as dissertaçóes baseadas na experiência administrativa como as de cunho bibliográfico teceram em texto um esqueleto de classificaçôes possível no ensino superior e aceito pelos professores responsáveis pela formação da nova geração de profissionais da administração colonial.

Como textos menores, as dissertaçôes em geral não foram publicadas, tendo sido armazenadas nos arquivos da biblioteca da ESC/ISEU. ${ }^{5}$ No contexto pós-colonial, os historiadores vislumbraram nessas narrativas marcas de preconceito e ausência de procedimentos metodológicos confiáveis. Tais peças do ensino permitem, no entanto, que sejam consideradas como fragmentos para uma reconstituição histórica que não reifique posiçóes de poder e seus efeitos centralizadores (Foucault, 1994). É nesse sentido que esses textos dissertativos serão colocados para uma análise das relaçôes construídas mediante a ação do Estado português no relacionamento com e para as sociedades africanas de Angola e das muitas manobras para que se garantissem as condições de autoridade e as estruturas de decisão política a partir de Lisboa, em um cenário de forte resistência política à ocupação colonial nos anos $1950 .^{6}$

\section{Estratégias discursivas e classificação social para Angola}

Algumas estratégias discursivas encontradas nos textos dissertativos do ensino superior metropolitano podem ser positivadas por meio de três aspectos que consideramos relevantes: 1) imagens de como as populaçóes africanas deveriam ser e sua não correspondência a esse padrão; 2) novas terminologias sociais que procuram descrever e ampliar as possibilidades de "problemas" a serem levados a conhecimento do Estado português, para além da "questáo indígena"; e 3) propostas de açáo social por parte do Estado para cada uma das esferas sociais identificadas com "necessidades" de intervenção.

Uma primeira estratégia identificada nesses textos diz respeito a duas formas de nomeação que coexistem: uma "ideal", referida a como o trabalhador africano deveria ser; outra "real", que designa como ele é.7 Os africanos de Angola foram 
considerados segundo um ideal esperado, que esteve muito próximo de uma realidade traduzida na experiência de trabalhadores europeus. Propunha-se, por exemplo, o enquadramento das populaçôes africanas à categoria de "agricultor", ou seja, um trabalhador rural. Esperava-se uma agricultura exemplar, eficiente e ordenada:

a extensão dos blocos de cultura e as espécies agrícolas a fomentar em cada regiâo são calculadas de modo a exigirem, inicialmente, um mínimo de 180 dias de trabalho por ano aos indivíduos considerados agricultores, média que náo se considera elevada nem difícil de atingir, em virtude de ser correspondente à média de dias de trabalho de um cultivador de algodão, de muitos cultivadores de café e daqueles tidos presentemente como de melhor nível de evolução. Por isso, é considerado agricultor todo aquele que preencha cumulativamente as seguintes condiçóes: a) ter residência permanente, em habitação melhorada, há mais de três anos, junto das suas terras em cultura ou em aldeamento que fique próximo; b) cultivar a área mínima que lhe for fixada pelos Serviços de Agricultura; c) possuir as plantas perenes que lhe forem indicadas, convenientemente tratadas, por mais de 3 anos; d) prestar ao gado de criação e de trabalho, onde for possível, os cuidados prescritos pelos Serviços de Veterinária; e) manter o solo protegido contra a erosão e seguir as demais prescriçóes técnicas necessárias às culturas, preparação e apresentação dos produtos (Soares, 1961:53).

Assim como aos agricultores, aos trabalhadores assalariados também seriam destinadas expectativas de submissão a uma ordem econômica que estavam longe de corresponder ao seu cotidiano. Castanheira (1950), por exemplo, expressa essa distância entre o real e o ideal referindo-se aos africanos do sul de Angola como 1) "relutantes ao trabalho por razóes étnicas", como os Cuanhamas que migram; 2) com um comportamento econômico marcado pela ambição, como os Ganguelas e Quiocos que recebiam melhor pagamento no estrangeiro; 3) ociosos, por estarem acostumados ao trabalho das mulheres, no caso, os Cacondas; 4) desorganizados familiarmente, resultado do recrutamento de trabalhadores para terras distantes (uma constante da ação colonial em Angola desde o início do século XX), características estas que os impediam de se fixar a trabalhos em empresas e grandes plantaçóes. Mendes, por seu turno, percebia o africano como condicionado por uma "lógica de usos e costumes que levaram séculos a criar-se" e de uma "perigosa existência que aprendera[m] de seus antepassados, de modo algum desejando relaçóes com o trabalho regular e constante” (Mendes, 1958:86).

Havia para esses jovens intérpretes da realidade colonial um descompasso no comportamento do africano trabalhador, cujo rendimento no trabalho não correspondia ao esperado, mas antes "coaduna[va] perfeitamente com a sua maneira 
de trabalhar, ou melhor, de preguiçar" (Mendes, 1958:64-65), "entregue[s] a si mesmo e sem força de vontade". "Preguiçosos", "vadios", muitas vezes "perigosos" para a política indígena (a partir da tensão dos movimentos de oposição, "subversivos", que nos anos 1950 passaram a preocupar o governo português), os africanos eram vistos nesses textos produzidos em Lisboa integrando uma realidade bem distante da desejada a um trabalhador (do campo ou assalariado).

Os padrôes classificatórios encontrados nas dissertaçôes sob análise apresentavam propostas de desenvolvimento econômico colonial que se mantinham submetidas às intençóes e aos interesses de grandes proprietários de terra e capital. A relação do governo português com as colônias é conhecida pela sua história de práticas contínuas de trabalho forçado e de construção de um sistema que conferia vantagens aos brancos sobre os negros e o acúmulo de riquezas de uns por meio do trabalho de outros (Penvenne, 1995; Pitcher, 1995). O "ultra-colonialismo" português, como o chamou Perry Anderson, sustentou grupos econômicos e o uso de mão de obra colonial barata como um meio de integração com a Europa, em uma posição de dependência de países mais "desenvolvidos" (Anderson, 1963; Cahen, 1997; Clarence-Smith, 1985). Os anos 1950 informam uma ordem política marcada pela continuidade dessas práticas apoiadas pelas forças armadas, pela polícia, pela igreja católica e por uma oligarquia de proprietários de terra, grupos industriais e financeiros. As revisóes da política colonial portuguesa da década de 1950 foram entendidas como cosméticas por Rui Pereira (1987), mantendo reformas sanitárias e escolares que situaram o africano como um "outro", distante da sociedade moderna (Pélissier, 1979), portanto ausentes de elaboraçóes surgidas de demandas locais (Cahen, 1997).

As classificaçôes sociais inscritas nas dissertaçôes estáo diretamente ligadas a esse cenário político e econômico nacional. O "problema" econômico está explícito nesses estudos. As referências às políticas de assistência social e aos modelos baseados em "justiça" e "igualdade" foram crescentes a partir do início de 1950, tendo sido o "negro" ou "africano" mantido nessas narrativas como principal objeto a ser conhecido. Em Angola, civilizar o "indígena” pelo trabalho havia sido uma "soluçáa”" para a falta de braços e o funcionamento dos serviços públicos e das culturas agrícolas obrigatórias; tal soluçáo era mantida necessária com a chegada cada vez mais numerosa de europeus ao território (Castelo, 2007).

Se as representaçóes podem ser atalhos de uma realidade complexa, diversa e multifacetada com o propósito de intervenção, como propôs David Scott (1998), os ideais formulados pelos alunos são produtos da configuração social específica, onde objetos são definidos e selecionados para a representação. A distância entre o trabalhador "ideal" e o "real" — ambos ficçôes — permitiu 
a escolha por determinados objetos, sua existência no texto e a produçâo de um modo de perceber a realidade colonial por parte dos especialistas em formação em Lisboa. O papel dos estudos era o de identificar as causas para a inexistência de trabalhadores e explicitar os motivos pelos quais o "trabalhador indígena" ou o "agricultor" não corresponderiam ao ideal esperado. Essa estratégia discursiva se organizava de forma criativa em cada um dos alunos, que enumeravam diferentes motivos para esse descompasso. Chama a atenção a forte presença, nesses textos, de consideraçôes a respeito da saúde do africano, ligada à alimentação, ao vestuário e à moradia, fazendo repercutir concepçóes da realidade africana formuladas por um dos professores da ESC, Antonio Augusto Mendes Correa, em seus estudos de antropologia biológica.

Complementar à idealização dos trabalhadores para a economia colonial, encontramos outra estratégia que estabelecia classificaçôes para os grupos sociais de Angola. Tendo sido, nas décadas anteriores, nomeadas exclusivamente por "indígenas" (com base em elementos raciais e culturais, como já referimos), os africanos receberam novas classificaçôes, como "agricultores" (Abrantes, 2014a), "produtores autônomos" ou "trabalhadores assalariados". Os "produtores autônomos", por exemplo, aparecem nos enunciados como merecedores de "igual tratamento" por parte do governo, que deveria reconhecer os seus "problemas" (Monteiro, 1959). Para além desses grupos profissionais, outro conjunto de problemas sociais passou a ser inscrito nos textos e tomado como relevante para o cenário da administração ultramarina: êxodo rural, vida familiar em crise, prostituição, criminalidade, delinquência juvenil, alcoolismo, má nutrição/subalimentação, más condiçóes de alojamento, desemprego, tirania dos líderes locais ("sobas") e imposição das autoridades administrativas portuguesas (Pereira Neto, 1960; Soares, 1961). Eram problemas tão numerosos que os próprios alunos consideravam a sua análise difícil. $\mathrm{O}$ objetivo dos estudos era o de revelar as características dos "condicionalismos" a que estavam expostas as sociedades africanas e, assim, desenhar seus "problemas sociais".

Nesse cenário, propagavam-se orientaçôes de que o "negro" não deveria ser colocado como máquina, mas antes como figura dotada de sentimentos, interesses e direitos a serem considerados pelos envolvidos nas dinâmicas econômicas e estatais. Esses novos termos descritivos substituíram as identificaçóes anteriores de "trabalho indígena", em especial nas dissertações que se propunham a um diálogo com as orientaçóes de organismos internacionais como a Organização das Naçôes Unidas (ONU) e a Organização das Naçóes Unidas para a Educação, a Ciência e a Cultura (Unesco), que mobilizaram as atençóes para os processos de descolonização e os posicionamentos de apoio e intervenção internacional 
em emergência naqueles anos. Nas dissertações em diálogo com a Organização Internacional do Trabalho (OIT), a identificação dos "trabalhadores indígenas" foi transmutada para "trabalhadores assalariados". Definia-se uma nova moral nas relaçóes das populaçóes com o Estado colonial que se tornaria propulsora do projeto assimilador para a integração das populações africanas à coletividade nacional portuguesa.

Sendo esse diálogo internacional uma constante - explícita (Castanheira, 1950; Mendes, 1958; Moura, 1955; Pereira Neto, 1960; Soares, 1961) ou implícita (Monteiro, 1959) —, é possível perceber uma terceira estratégia colocada em jogo: a importância da açáo administrativa, do Estado, como soluçáo para os comportamentos distantes do ideal esperado. No decorrer dos anos 1950, a antiga fórmula colonial de civilizar os "indígenas", ainda introduzida em uma das primeiras dissertaçóes defendidas, a de Américo Castanheira (1950), foi diluída em afirmaçôes sobre campanhas educativas e açôes de assistência social, o que multiplicaria as possibilidades de ação de um Estado tutelar. ${ }^{8}$ Ao serem nomeados como "incapazes", os africanos de Angola continuariam a ser objetos privilegiados de uma açáo reparadora que passou a ser imaginada sob novos paradigmas administrativos, pautados por programas educativos que oferecessem a continuidade de "transformaçáo" dos trabalhadores sem uso da força (castigos físicos). Ao Estado, seria dada a função de "aliviar a sobrecarga fastidiosa vivida pelo indígena" (Mendes, 1958), formular um sistema que organizasse as relaçóes trabalhistas de forma mais "justa e humana”, adequar o indígena ao perfil do "trabalhador assalariado" (para obter autonomia financeira, utilizar recursos de forma eficiente e obter hábitos alimentares saudáveis), e corrigir "abusos" praticados por autoridades administrativas e capatazes de empresas. Nesses relatos de alunos, formulavam-se críticas aos métodos coloniais antigos, considerados abusivos e incoerentes, uma possibilidade narrativa que levaria o aluno a "melhor situar[-se] dentro das realidades presentes" (Mendes, 1958:13-14), ou seja, em adequação às pressóes internacionais que tinham como objetivo reduzir a desigualdade colonial.

O Estado foi designado a atuar nos espaços em que se detectaria uma "diferença civilizacional", termo que supunha uma dependência das sociedades africanas dos portugueses e a centralidade das açóes dos representantes estatais. Propunha-se a assimilação e a tutela enquanto não se alcançasse nas colônias um "sistema de trabalho e mercado livres", uma "estrutura social saudável e planejada", o "equilíbrio nos modos de subsistência" e a "garantia de direitos e benefícios" para as populaçôes. Esperava-se que a presença da administração colonial a partir de 1954 se desenrolasse nos termos de uma política "idônea" (Monteiro, 1959), que fizesse "valer direitos", considerasse os "efeitos sociais das políticas" na vida 
regional, identificasse "benefícios para os africanos" e alcançasse uma "promoção legítima da vida social", sem, no entanto, abrir mão dos projetos assimilacionistas. Populaçôes ideais e reais e todo um novo conjunto de identificadores sociais mantinham a possibilidade de criar programas de ação administrativa, uma "brigada de técnicos", "planos de ação polivalentes" e uma "nova máquina de gestão ultramarina” (Pereira Neto, 1960; Soares, 1961) que fizesse cumprir os regulamentos portugueses e as orientaçóes da política ultramarina remodelada na base da "justiça” e "igualdade". O Estado português se manteria operante e necessário desde que existissem populaçóes merecedoras de seus cuidados.

As novas orientaçôes repercutiram nas outras dimensôes do cenário colonial. Em 1955, a legislação detalhou as condições de trabalho nas colônias, com horas limitadas, obrigatoriedade de remuneração, salário mínimo, exclusão das sançôes penais para quebras de contrato de trabalho e inspeção do trabalho. Camponeses foram assim incentivados a produzir commodities, muito embora em desvantagem dentro de um mercado competitivo orientado pela tecnologia (mecanização) e carente de trabalhadores assalariados "disciplinados", "válidos" e "saudáveis". A moral do trabalho foi mantida com a afirmação de um direito do Estado para estabelecer métodos de trabalho para o desenvolvimento das condiçôes sociais e individuais dos africanos (Pitcher, 1995). Muitos africanos recusaram-se a assinar contratos de trabalho, o que sinaliza para a imposição de certos "direitos". O tom de "benefícios" substituiu o de "coerção", mantendo firme a demanda e os interesses dos setores econômicos — como o algodão, principal produto da economia de Angola.

As estratégias discursivas que identificamos correspondem às transformaçôes de uma linguagem destinada a favorecer a indústria e o povoamento de europeus dentro de um mercado mais flexível, que operaria por meio do "trabalho livre". Com elas, desenhava-se o espaço para uma alta gestão colonial conhecedora das "modernas" regras de administração e, ao mesmo tempo, das "carências", "faltas", "necessidades", "abusos" e "demanda por direitos" de populaçôes coloniais. Os alunos, diplomados e autores das dissertaçôes estavam posicionados no interior de uma estrutura que se reorganizava não apenas em termos dos enunciados, mas das relaçóes sociais que também sofreram modificaçôes no período, como veremos adiante.

\section{O lugar social das dissertaçóes de licenciatura e seus autores}

Em finais dos anos 1940, José Gonçalo da Costa Santa Rita, professor da ESC, chamava a atenção para a situação crítica em que se encontravam os países colonizadores, alvos de denúncias e de opiniôes nem sempre favoráveis à presença 
europeia nos territórios coloniais (Santa Rita, 1946). A reestruturação da Escola ocorreu nesse contexto de resposta de grupos metropolitanos aos movimentos políticos de ampla envergadura internacional e em conexão às tentativas de "cooperaçáo" entre instituiçôes de pesquisa para discutir os "problemas coloniais". A ESC figurava como um dos espaços de formulação e expressão dos novos modelos administrativos, que passaram a ser dispostos em um enquadramento mais amplo de proposiçóes emitidas em outros cenários europeus.

As dissertaçôes permitem identificar as discussôes levadas a cabo pelos organismos internacionais, tais como OIT, Unesco e ONU, e as interpretaçóes locais no cenário do ensino de português. Os professores das cadeiras de política (ultramarina e internacional), Adriano Moreira e Antonio da Silva Cunha, foram membros ativos nas discussões da ONU e OIT, posicionando-se diante dos procedimentos criados nessas instâncias e expressando suas opiniôes em publicaçóes internas - textos de leitura obrigatória no ensino da nova geração de administradores. As dissertaçóes de Castanheira (1950), Moura (1955) e Mendes (1958) contêm informaçôes sobre as comissóes organizadas pela OIT e articulam uma traduçáo da linguagem internacional sobre o "trabalho indígena”, adequando-a às normatividades internas, portuguesas, em especial, referidas ao Código de Trabalho Indígena (Abrantes, 2014b). Por sua vez, as formulaçóes e orientaçóes nas dissertaçóes de Soares (1961) e Pereira Neto (1960) estão voltadas para a tradução de uma nova gramática desenvolvimentista, de cooperação técnica para o desenvolvimento, proposta a partir da ONU e Unesco.

Essa orientaçáo para o exterior está circunscrita à retomada, a partir dos anos 1950, de negociaçóes em relação ao uso do trabalho forçado por Portugal, que ratificou em 1956 a convenção de 1930, do Trabalho Obrigatório (Rodríguez-Pińero, 2005). Em 1957, um representante português foi enviado à OIT para participar da elaboração da nova convençáo que estabelecia as regras para a integração das populaçôes indígenas aos países independentes. Portugal ratificou-a em 1960, sob a alegação de que era um "país independente" pluricontinental com presença de populaçôes indígenas - argumento que teria servido para legitimar a continuidade do colonialismo diante da comunidade internacional (Rodríguez-Piñero, 2005). ${ }^{\text {? }}$

Alguns alunos mais proeminentes dessa formação especializada, como Pereira Neto e Castilho Soares, passaram a participar de reunióes promovidas pelos organismos internacionais para as recentes naçóes independentes africanas (na virada da década de 1960). Como representantes de uma naçáo que se constituía por territórios continentais e ultramarinos, os interlocutores portugueses, brancos, colocavam-se como porta-vozes das populaçóes africanas, 
criando constrangimentos em meio a discussóes sobre a autonomia dos povos (naçóes independentes) e o direito à diferença (populaçóes indígenas) em que participavam as novas lideranças dos governos independentes africanos. Isso revelava uma agência portuguesa muito particular, tantas vezes criticada ao longo da história por sua persistência e esforço a qualquer preço em manter sob domínio as possessôes estrangeiras.

Para além dos organismos internacionais centrais, espaços laterais foram criados nessa ocasião, como a Cooperação Técnica em África ao Sul do Saara (CCTA) e o Institut International des Civilizations Différentes (INCIDI), para discutir os "problemas de África" e reunir especialistas e saberes necessários ao progresso do continente para uma "organização de um sistema eficaz de cooperação", ligado a uma "revisão da carta política da África” (Silva Cunha, 1957:133). ${ }^{10}$ As adesóes a essas comissóes vieram de alguns professores, como João da Costa Freitas, representante nas discussóes do CCTA, e Jesus Nunes dos Santos, nos trabalhos do INCIDI e CCTA em finais de 1950, ambos com grande influência na dissertação de Soares (1961).

A ideia de cooperação se daria não apenas em termos técnicos, mas também "políticos", já que a África vinha sendo de pouco interesse para a ONU e a proposta do CCTA era diferenciada, segundo alegavam os seus propositores, em especial o seu primeiro secretário-geral, Henry Paul-Marc, francês formado pela École Nationale d'Administration. O esforço seria o de reunir pesquisadores de campo e cientistas na África em uma rede de comunicação comum, encorajando o uso de recursos de forma mais eficaz, buscando uma "fórmula para a cooperação". Assim, a "cooperação técnica na África" seria uma preocupação não apenas dos países membros, mas também das agências governamentais, consideradas "governos de fora” (outside governments) (Gruhn, 1971:460). Segundo Gruhn (1971), Portugal não possuía cientistas ativos, embora contribuísse para o orçamento da CCTA e tivesse, em 1962, reagido de forma enérgica ao ser convidado a se retirar, alegando estar sendo ameaçado dos seus direitos de participação. Sua presença como um país independente lado a lado com os países recentemente autônomos africanos não parecia se equacionar aos novos modelos de ação propostos pelos ideários da "co-operação" em África.

As formulaçôes em torno dos "problemas coloniais" foram também tecidas e interpretadas à luz de heranças teóricas e posições políticas locais. Professores das décadas anteriores, ainda ativos no contexto da reforma do ensino superior de 1946 - como Lopo Vaz de Sampaio e Melo, José Gonçalo da Costa Santa Rita, Antonio de Almeida e Antonio Augusto Esteves Mendes Correa —, forneceram as bases curriculares para a reorganização do ensino, a implementação do curso 
especializado e a reformulação do curso básico, que teve a sua carga horária e duração reduzidas pela reforma de 1946 (de quatro para três anos).

As áreas do direito e da economia passaram a ser centrais na formaçáo especializada, onde assuntos foram "nacionalizados" e "internacionalizados". As cadeiras de "Política Colonial", "Direito Internacional Colonial" e "Economia Colonial" absorveram os conteúdos de "Política Indígena", configurando-se como um conteúdo a ser revisitado em um cenário em que medidas dirigidas às populaçóes "indígenas" eram terrenos minados — e, como vimos, passaram a ser de responsabilidade da OIT. ${ }^{11}$ Nos anos finais da década de 1950, professores conectados a essas temáticas, como Silva Cunha, perderam espaço no interior da instituição de ensino para outros profissionais cujas temáticas eram mais propícias a um melhor "entendimento" das reais "necessidades" das populaçôes. A naçáo pluricontinental estava em vias de abolir o Estatuto do Indigenato, regulamentação gestada nos anos 1930 que perderia legitimidade com as novas regras da política internacional. Negociava-se, no contexto mais amplo, a transferência de responsabilidades dos problemas das populaçôes designadas por "indígenas" para esferas de agência internacional, no caso, a OIT, espaço que oferecia a proteção de seus direitos e defesa de seus interesses.

Assim, conteúdos de "Política Indígena" foram absorvidos pela cadeira "Instituiçóes Nativas", que tratava do conhecimento sobre as populaçóes africanas com conteúdos etnológicos e de etnografia colonial, herdeiros das atividades docentes de Mendes Correia, que a partir de 1956 foram traduzidos por Jorge Dias pela lente da antropologia cultural. $\mathrm{O}$ professor contratado na esteira da reforma de 1946, Adriano Moreira, passou a ocupar a posição de seu antecessor Santa Rita, renovando olhares à luz das abordagens teóricas do direito e das ciências sociais. Ressalta-se ainda a colaboração, no projeto de revisão do ensino superior, do professor Antonio da Silva Rego, que formulou avenidas para uma história colonial onde os "abusos" passaram a ser referidos a uma "velha" administraçáo colonial em substituição. A renovação dos quadros docentes e a aposentadoria de Santa Rita e Mendes Correa, em 1958, modificaram definitivamente a paisagem temática de ambos os cursos (especializado e básico) de administraçáo oferecidos pela instituição, em que se buscou apagar as arestas remanescentes do saber colonial.

Gilberto Freyre, sociólogo brasileiro, convidado para uma missão às colônias em 1951, mencionava ter percebido a mudança de atitude dos profissionais do Estado português naqueles anos:

a sua integração [dos indígenas] na nova cultura que se esboça na África pela acção da presença, não de simples "lançados" mas de portugueses agora sistematicamente organizados pela obra de lusitanização de terras há muito 
tempo pertencentes a Portugal, é uma integração que deve processar-se lentamente. Sem violências policiais contra os indígenas: os futuros portugueses, e sob alguns aspectos já portugueses; e não vagos e estranhos "negros" ou "bárbaros", que é o que enxergam neles muitos — de modo algum todos — dos seus dominadores ingleses, belgas, holandeses (Freyre, 1952:210-211).

Essa afirmativa correspondia ao contexto de reformulaçáo do ensino e reorganização dos saberes pelos gestores em Lisboa (Freyre, 1952). A expectativa anunciada era de que os futuros quadros do governo passariam a ter bases mais sólidas para enfrentar a integração das populaçôes ao projeto nacional por meio de uma nova gramática que não repetisse os "erros" das políticas de violência anteriores e/ou dos governos coloniais vizinhos. René Pélissier (1965, 1980), ao selecionar algumas das dissertaçóes para análise nos anos 1960, também "testemunhava" o esforço dos representantes do governo em Lisboa no sentido de "melhorar o conhecimento dos seus territórios" e, portanto, corrigir as atitudes de governos anteriores.

Assim, as dissertaçóes foram produtos dessa reconfiguração teórico-política interna, além das adesôes às propostas das gramáticas da cooperação internacional, permitindo uma análise das modificaçôes nas estruturas de relaçôes sociais entre Europa e territórios coloniais africanos e asiáticos. ${ }^{12}$ Nessa conjuntura, novos espaços institucionais na metrópole portuguesa nasceram orientados para pesquisas e organização de informaçóes trazidas das colônias, o que garantia a legitimidade e aceitação das práticas governamentais ultramarinas. O Gabinete de Negócios Políticos (GNP), por exemplo, criado em 1959 no Ministério do Ultramar — a partir do professor Adriano Moreira —, tinha a função de analisar a informação que chegava abundante dos dispersos governos provinciais: das inspeçôes, dos serviços ultramarinos e da imprensa mundial (Moreira, 2004 apud Silva, 2008). Como um órgão executivo, o GNP distinguia-se das atividades de ensino e de investigação de competência do ISEU e da Junta de Investigaçóes do Ultramar (JIU) (Castelo, 2007). Entretanto, ajustava-se às novas formas de comunicação e manutenção de laços (Goody, 1986) entre metrópoles parceiras e colônias subalternas que foram projetadas como resultado das transformaçóes das agências coloniais desse período.

A absorção dos ex-alunos do curso complementar na máquina administrativa permite visualizar a rede administrativa e, ao mesmo tempo, a centralidade que a ESC/ISEU obteve ao longo da década de 1950 nas orientaçóes da política colonial portuguesa. Castilho Soares, após a conclusão do curso de especialização, ocupou a Secretaria de Educação do Governo de Angola, Américo Castanheira esteve sob a responsabilidade do Governo de Distrito da Huíla (sul de Angola) e José 
Monteiro integrou a equipe do GNP. Afonso Mendes foi designado o primeiro presidente do Instituto do Trabalho, Previdência e Assistência Social, órgão criado em Angola na sequência da extinção da Repartição de Negócios Indígenas, em 1961, que absorveu muitos dos formados pelo curso básico e complementar do ISEU, dadas as questóes trabalhistas pautadas pelas diretrizes da OIT. ${ }^{13}$ Os "indígenas" transformados em "agricultores" passaram a ser regulados por uma legislação referida ao mundo rural e, portanto, mantidos sob regulação do Estado colonial — distantes da interferência das novas regulamentaçóes que estabeleciam autonomia e direitos das populaçóes autóctones, definidas pela OIT. ${ }^{14}$

Para além das posiçóes nas colônias que absorveram esses especialistas, a própria instituição de ensino ampliou o número de vagas para professores do ensino em administração colonial. Esse foi o destino, por exemplo, de Pereira Neto, que assumiu o cargo de professor da instituição ao concluir a especialização. Desse lugar, as dissertaçóes passaram a ser manuais para os mais jovens, alunos aprendizes do curso básico, que sonhavam com uma posição (de fronteira) na administração colonial, nos duros anos de reconstrução europeia pós-Segunda Guerra Mundial. Das dissertaçôes sobre Angola analisadas, é a de José Monteiro (1959) a que melhor apresenta essa narrativa destinada aos alunos da formaçáo básica. Sua linguagem estabelece um leitor cativo. Das 258 páginas, encontramos um vasto conjunto de termos voltados para uma administração jovem: "bom senso", "prudência" e "humanidade". O autor condicionava, em sua escrita, o modo de olhar dos futuros administradores escolhendo de antemão os instrumentos de ação a serem utilizados nas situaçôes de contato com os "indígenas". Assim, o texto de Monteiro se apresentava como um exemplo do novo espaço de ação colonial desenhado nessa configuração histórica particular: uma gramática e métodos pedagógicos destinados aos aprendizes de uma "política colonial idônea", que teriam, em contato com o texto, a oportunidade de conhecer as diversas situaçóes que iriam enfrentar na fronteira.

Vimos, assim, que por meio das dissertaçôes é possível colocar em relevo as novas relaçóes que se desenharam entre metrópoles e colônias no contexto que antecedeu as independências, vislumbrando-se o lugar do ensino superior como central para o acesso não apenas à administração, mas também a um novo conjunto de comportamentos esperados dos funcionários que garantisse a legitimidade da presença europeia no continente africano.

\section{Conclusóes}

Como produtos de uma instituição de ensino em dada conjuntura histórica, as dissertaçôes de licenciatura permitiram uma análise das mudanças nas 
gramáticas que se estabeleceram no contexto do colonialismo português tardio. Considerando-se as narrativas referidas a Angola, em especial orientadas para propostas de relacionamento com as então populaçóes "indígenas" e africanas, identificou-se uma tendência para classificar tais populaçóes dentro de certos padrôes discursivos. Propôs-se pensar em três estratégias como principais motores de ação colonial que podem ser depreendidas dos textos escritos pelos alunos do ensino superior: a) as formulaçôes de trabalhadores que não correspondiam a um ideal, b) a ampliação das classificaçóes sociais consideradas problemáticas, para além da categorização de "indígena” e c) a ideia compartilhada de um Estado imaginado mediante uma relação de dependência que seria responsável pela administração das populações sem incorrer nos vícios e "abusos" do passado.

As antigas açôes coloniais baseadas em castigos físicos, captura de populaçôes autóctones para o trabalho em empresas privadas e em empreendimentos públicos, e em todo um conjunto de procedimentos que colocavam o africano como trabalhador forçado, passaram a ser criticadas à luz de um novo ideário, que inspirou práticas mais "humanas". O Estado colonial, antes "capataz", passou a ser imaginado como um Estado colonial "benevolente", caracterizaçóes projetadas nos discursos dos jovens candidatos a "especialistas coloniais". Os alunos incorporaram em seus discursos as novas orientaçôes de respeito para com as populaçóes colonizadas sem, no entanto, abrir mão dos ideais de colonização pautados por paternalismo e tutela, esquema de ação já antigo nos projetos de ocupação e posse dos territórios além-mar e de relacionamento com a diferença.

Assim, as representaçôes sobre os "indígenas", "agricultores", "deslocados", "destribalizados", "analfabetos" etc. não teriam relação direta com o controle — como usualmente se pensa a transmissão da ideologia colonial por meio de uma instituição de ensino como a ESC/ISEU. Antes, o controle seria um efeito do ato de nomear - caracterizar populaçôes "problemáticas" e Estados "capazes" —, ato este que também contribuiria para a organização de grupos em posiçôes de poder. Os discursos desses alunos exerciam um tipo de poder que se alimentava dessa nomeação. No processo de representação, produziam-se especialistas nessas ações que ocupariam posições na administração colonial, fortalecendo os laços administrativos em função da capacidade para refletir sobre os "problemas" das colônias.

As dissertaçôes informaram o lugar de inscrição de determinados modelos de administração colonial e também os espaços de agência para a nova geração de indivíduos posicionados por sua profissão nas relaçôes entre Portugal, os países europeus e os territórios africanos. Por meio delas, é possível situar adesóes teórico-políticas internas à instituição de ensino e assinalar reconfiguraçóes de 
cooperação e responsabilidades externas, em conexão com outras instituiçôes de ensino superior europeias e organismos internacionais cada vez mais atuantes no contexto posterior à Segunda Guerra Mundial.

A inscrição das proposições nos textos dos alunos da instituição de ensino criava, na prática, o lugar social dos alunos especializados em identificar populaçóes "diferentes" e sobre elas equacionar propostas de intervenção de Estado. Tal posição social fora criada com a estruturação do ensino em 1946, o que sugere modificaçôes nas estruturas subjacentes às relaçóes assimétricas, permitindo que especifiquemos a sua direção e força motivadora (Wolf, 2003). O colonialismo português, com sua duração para além do tempo das descolonizaçôes dos anos 1960 e a forma pitoresca com que seus agentes se posicionaram no cenário de discussóes orientadas para a democracia e a participação política, desencadeia um conjunto de reflexóes em torno dessa estrutura organizada em novas formas de dominação, e o caráter dos relacionamentos que a partir daí se vislumbraram entre as ex-metrópoles e as ex-colônias.

O universo empírico acessado pelas dissertaçóes de licenciatura — produtos finais do ensino superior metropolitano em administração colonial — abre possibilidades de uma compreensão das configuraçóes sociais envolvidas no desenvolvimento de saberes administrativos projetados para territórios longínquos com base em diferenciaçóes de "nós" e "eles", nos efeitos assimiladores e homogeneizadores, e principalmente nos pressupostos para o exercício de uma vocação imperial. A análise micro, em um contexto de ensino superior muito particular, como a que procuramos empreender, permitiu, assim, um entendimento mais profundo do processo de conquista de territórios cujos bastidores continuam imersos no silêncio e esquecidos pela história.

Recebido em 15/06/2015.

Aceito em 12/09/2015.

Carla Susana Alem Abrantes é professora dos cursos de graduação em humanidades e em antropologia da Universidade da Integração Internacional da Lusofonia Afro-Brasileira (UNILAB), em Redenção, no Ceará. Defendeu sua tese de doutorado em 2012 com o título "Problemas" e "soluçôes" para a gestão de 
Angola: um estudo a partir do ensino superior de administração colonial, 1950-1960, no Programa de Pós-Graduação em Antropologia Social do Museu Nacional, da Universidade Federal do Rio de Janeiro (PPGAS/MN/UFRJ). Suasáreas de interesse de pesquisa são pensamento social, colonialismo e administração colonial. É líder do grupo de pesquisa Cooperação Internacional e Tradiçóes de Conhecimento e pesquisadora do LACED/MN/UFRJ — Laboratório de Pesquisas em Etnicidade, Cultura e Desenvolvimento. Contato: sabrantes@gmail.com

\section{Notas}

1. A Escola Colonial foi criada em 1906 a partir dos desígnios da Sociedade de Geografia de Lisboa (SGL). Em 1926, passou a ser designada Escola Superior Colonial (ESC), considerada a "escola das escolas" em razão da sua participação ativa na divulgação da ideia de Portugal como um país colonial (Paulo, 1992). Em 1954, foi transformada em Instituto Superior de Estudos Ultramarinos (ISEU) pela especialização em "problemas" do Ultramar diante das necessárias reformas de um país que deixou de ser, formalmente, uma metrópole colonial para se transformar em um Estado Nacional com territórios estrangeiros dependentes — as "províncias ultramarinas". Em 1961, foi designado por Instituto Superior de Ciências Sociais e Política Ultramarina (ISCSPU) e vinculado à Universidade Técnica de Lisboa (UTL).

2. Decreto-Lei no 35.885, de 30 de setembro de 1946; Portaria Ministerial no 11.885, de 12 de junho de 1947.

3. Decreto-Lei $\mathrm{n}^{\circ} 35.885$, de 30 de setembro de 1946.

4. 80 dissertaçôes foram produzidas sobre Angola entre 1949 e 1971, entre as quais 17 versaram sobre política indígena, ou seja, sobre as populaçóes a quem se destinavam os projetos de intervenção estatais coloniais concebidos em Lisboa.

5. Das seis dissertaçóes aqui analisadas, duas foram publicadas pela revista da instituição: Mendes (1958) e Soares (1961).

6. Os alunos foram aprendizes de um sistema de gestão ultramarina em construção nos anos 1950 e, portanto, candidatos ao que Émile Durkheim (1983:4-46) denominou como "grupo especial" pela possibilidade de produzir, incorporar, encenar ideias sobre o Estado e a sociedade sobre a qual teriam o poder de intervir. Durkheim define o Estado como um corpo específico de funcionários com legitimidade para serem porta-vozes de uma coletividade: sua função principal seria se responsabilizar pelas definiçôes do que a sociedade é, como deveria ser e que açôes deveriam ser propostas em seu nome.

7. Frederick Cooper e Ann Stoler (1997) fazem referência às representaçôes dicotômicas entre colonizadores e colonizados como dominantes nos discursos do contexto colonial, em que ideais de uma sociedade colonial foram formulados. Tais representaçôes binárias funcionaram como uma operação ideológica, obscurecendo outros entrelaçamentos sociais, tais como raça, etnicidade, gênero e classe. 
8. Como uma forma de entender e agir no mundo, a tutela pressupóe a existência de um código de condutas partilhado por todos os membros do grupo em relaçáo à percepção da diferença, levando a açóes educativas que se transformam em necessárias, e que revestem a relação entre o "tutor" e o "tutelado", como propóe João Pacheco de Oliveira (1988).

9. Esse argumento político foi avaliado e criticado pelas comissóes criadas, principalmente na ONU, em 1960, que investigaram as condições na "África portuguesa" e questionaram a afirmação de uma nação pluricontinental (Martelli, 1969).

10. Os governos europeus procuraram coordenar os esforços dirigidos para a África com discussões iniciadas em 1945 com França e Inglaterra, acompanhadas de Bélgica, Portugal, África do Sul e Rodésia (atual Zimbábue). Dez anos depois da criação do CCTA, em 1950, a participação e a representaçáo africanas passaram a ser propostas de forma imperativa. A primeira nação africana a ingressar como membro foi Gana, em 1958, sendo que em 1960 o CCTA já contava com 18 outras nações independentes, com um movimento de mudança da sede na Europa para a África e a exclusão do direito a voto dos membros fundadores na reunião de 1962 em Abidjan. Segundo Gruhn (1971), a CCTA era uma organização ocidental transplantada para o solo africano, que passou a ser "africanizada", ou seja, promovida pelos países independentes por meio de orientaçóes e agendas próprias até 1965 , passando a contar também com países do norte da África até ser absorvida pela Organização da Unidade Africana (OUA).

11. No curso básico de administração colonial, a antiga cadeira de "Política Indígena", criada em 1926 pelo professor Lopo Vaz, abrigava as diretrizes a serem seguidas no relacionamento com as populaçóes africanas. Autor de um livro publicado em 1910 que recebera o mesmo nome da cadeira, Política indígena - que foi considerado uma das fontes de inspiração para as descriçôes do continente africano apresentadas aos alunos (Paulo, 1992) —, Lopo Vaz propunha dar a conhecer as diferentes açóes da política de integração das populaçôes à vida da colônia, cabendo ao Estado o papel de agente de assimilação pelo ensino da língua portuguesa.

12. Em 1946, a criação do curso complementar, especializado, também atendia a demandas políticas do Ministério das Colônias, na altura sob a responsabilidade de Marcelo Caetano, em sua política de aproximação da realidade africana, com intençóes de descentralização administrativa e harmonizaçáo dos processos de governo entre metrópole e colônias (Valente, 1999).

13. A Secretaria dos Negócios Indígenas de 1913 foi criada para tratar dos assuntos "indígenas" (trabalho, justiça, serviço militar, impostos e outros) na sequência da legislaçáo laboral de 1899, tendo sido ligada às propostas elaboradas por Antonio Ennes, considerado um dos pais da moderna política colonial portuguesa (Duffy, 1959).

14. Código de Trabalho Rural. Decreto-Lei no 44.309, de 27 de abril de 1962. 


\section{Referências bibliográficas}

ABRANTES, Carla Susana Alem. 2014a. "Repertórios do conhecimento em disputa: trabalhadores indígenas e agricultores no colonialismo português em Angola, 1950". Anuário Antropológico, 39(1):195-218.

. 2014b. "Narrativas para a gestão de Angola: o 'índigena' como objeto de estudo no ensino superior, 1950-1960". In: Selma Pantoja \& Estevam Thompson (orgs.). Em torno de Angola: narrativas, identidades e conexöes Atlânticas. Lisboa: Intermeios/ PPGDSCI. pp. 33-48.

ANDERSON, Perry. 1963. Le Portugal et la fin de l'ultra-colonialisme. Paris: François Maspero.

ANTUNES, Luís F Dias \& RODRIGUES, Vítor L. Gaspar. 2011. "A escola colonial e a formação de uma 'elite dirigente' do ex-ultramar português (1906-1930)". Africana Studia: Revista Internacional de Estudos Africanos, 17:41-49.

Anuário da Escola Superior Colonial. 1947. Lisboa: Escola Superior Colonial. Ano XXVIII.

ASAD, Talal. 1973. Anthropology and the colonial encounter. New York: Humanities Press.

BASTOS, Cristiana. 2007. "Um centro subalterno? A Escola Médica de Goa e o império”. In: Cristiana Bastos, Miguel Vale de Almeida \& Bela Feldman-Bianco (orgs.). Trânsitos coloniais: diálogos críticos luso-brasileiros. Campinas, SP: Editora da Unicamp. pp. 143-161.

CAHEN, Michel. 1997. "Salazarisme, fascisme et colonialisme: problèmes d'interprétation en sciences sociales, ou le sébastianisme de l'exception". Instituto Superior de Economia e Gestão - CESA. Documento de Trabalho, 47.

CASTANHEIRA, Américo. 1950. "Trabalho indigena": algumas consideraçôes acerca do problema da mão de obra indígena nas colônias de Timor e de Angola. Lisboa: Instituto Superior de Estudos Ultramarinos.

CASTELO, Cláudia. 2007. Passagens para a África: o povoamento de Angola e Moçambique com naturais da Metrópole (1920-1974). Lisboa: Afrontamento.

. 2012. "Investigação científica e política colonial portuguesa: evolução e articulaçóes, 1936-1974”. História, Ciências, Saúde, 19(2): pp. 391-408.

CLARENCE-SMITH, William Gervase. 1985. The Third Portuguese Empire 18251975: a study in economic imperialism. [s.1.]: Manchester University Press. 
COMAROFF, John. 1997. "Images of empire, contests of conscience - models of colonial Domination in South Africa”. In: Ann Laura Stoler \& Frederick Cooper (eds.). Tensions of empire: colonial cultures in a bourgeois world. Berkeley/Los Angeles/London: University of California Press. pp. 163-197.

CONCEIÇÃO NETO, Maria da. 1997. "Ideologias, contradiçóes e mistificações da colonização de Angola no século XX”. Lusotopie, pp. 327-359.

COOPER, Frederick \& STOLER, Ann Laura. (eds.). 1997. Tensions of empire: colonial cultures in a bourgeois world. Berkeley/Los Angeles/London: University of California Press.

DIRKS, Nicholas. 1992. Colonialism and culture. Michigan: The University of Michigan Press.

DUFFY, James. 1959. Portuguese Africa. Cambridge, Massachussetts, London: Harvard University Press, Oxford University Press.

DURKHEIM, Émile. 1983. Liçôes de sociologia: a moral, o direito e o Estado. São Paulo: T. A. Queiroz/USP.

ELIAS, Norbert. 1994. Os alemães: a luta pelo poder e a evolução do habitus nos séculos XIX e XX. Rio de Janeiro: Zahar.

. 2002. "Processos de formação de Estados e construção de nações". In: F. Neiburg \& L. Waizbort (orgs.). Escritos \& ensaios. Rio de Janeiro: Zahar.

FOUCAULT, Michel. 1994. “'Omnes et singulatim': vers une critique de la raison politique". In: . Dits et Écrits 1954-1988. Paris: Gallimard. v. IV (1980-1988), pp. 134-161.

2010. "Ciência e saber". In: . Arqueologia do saber. Rio de Janeiro:

Forense Universitária, pp. 201-222.

FREYRE, Gilberto. 1952. Aventura e rotina: sugestóes de uma viagem à procura das constantes portuguesas de caráter e ação. Lisboa: Livros do Brasil.

FRY, Peter. 2003. "Culturas da diferença: sequelas das políticas coloniais portuguesas e britânicas na África Austral”. Afro-Ásia, 29/30:271-316.

GALLO, Donato. 1988. Antropologia e colonialismo: o saber português. Lisboa: Edição ER - O Heptágono.

GOODY, Jack. 1986. A lógica da escrita e a organização da sociedade. Lisboa: Ediçōes 70.

GRUHN, Isebill V. 1971. "The Commission for Technical Co-operation in Africa, 1950-65”. The Journal of Modern African Studies, 9(3):459-469. 
LEAL, João. 2006. Antropologia em Portugal: mestres, percursos, tradiçōes. Lisboa: Livros Horizonte.

MAMDANI, Mahmood. 1996. Citizen and subject: contemporary Africa and the legacy of the late colonialism. Princeton, New Jersey: Princeton University Press.

MARTELLI, George. 1969. "The issues internationalized". In: Portuguese Africa: a handbook. New York, Washington, London: Praeger.

MATOS, Patrícia F. de. 2006. As côres do Império: representaçōes raciais no império colonial português. Lisboa: Imprensa de Ciências Sociais.

MENDES, Afonso. 1958. A Huila e Moçâmedes: consideraçôes sobre o trabalho indigena. Lisboa: Ministério do Ultramar, Junta de Investigaçóes do Ultramar.

MENESES, Maria Paula. 2010. "O indígena africano e o colono 'europeu': a construção da diferença por processos legais". In: E-Cadernos - CES. 7a. ed. pp. 68-93.

MONTEIRO, José Abelberto Pereira. 1959. O problema do trabalho dos indígenas. Lisboa: Dissertaçáo, Instituto Superior de Estudos Ultramarinos (ISEU).

MOURA, João Herculano Rodrigues de. 1955. A Organização Internacional do Trabalho $e$ os territórios dependentes: normas de politica social. Lisboa: Dissertação, Instituto Superior de Estudos Ultramarinos (ISEU).

OLIVEIRA, João Pacheco de. 1988. "O nosso governo": os Ticuna e o regime tutelar. São Paulo: Marco Zero; Brasília: MCT/CNPS.

PAULO, João Carlos Duarte. 1992. "A honra da bandeira": a educação colonial no sistema de ensino português (1926-1946). Lisboa: Faculdade de Ciências Sociais e Humanas da Universidade Nova de Lisboa.

. 2001. "Cultura e ideologia colonial". In: Joel Serrão \& A. H. Marques (dir.). Nova história da expansão portuguesa: o império africano (1890-1930). Lisboa: Estampa. v. VI, pp. 30-88.

PÉLISSIER, René. 1965. "L'Afrique portugaise dans les publications de la Junta de Investigações do Ultramar (Lisbonne)". Acta Africana, 4(2):249-270.

. 1979. Le naufrage des caravelles: études sur la fin de l'Empire Portugais (19611975). Orgeval, França: Pélissier.

. 1980. Africana: bibliographies sur l'Afrique luso-hispanophone (1800-1980).

Orgeval, França: Pélissier.

PELS, Peter. 1997. "The anthropology of colonialism: culture, history and the emergence of Western governmentality”. Annual Review of Anthropology, 26:163-183. 
PENVENNE, Jeanne. 1995. African workers and colonial racism: Mozambican strategies and struggles in Lourenço Marques, 1877-1962. Portsmouth; Johannesburg; London: Heinemann; Witwatersrand University Press; James Currey.

PEREIRA, Rui. 1987. "O desenvolvimento da ciência antropológica na empresa colonial do Estado Novo". In: Colóquio sobre o Estado Novo - das origens ao fim da Autarcia (19261959): colóquios sobre o Estado Novo. Lisboa: Fragmentos. pp. 89-100.

PEREIRA NETO, Joáo. 1960. O progresso econômico e social das populaçôes indígenas: na África do Sul do Saara. Lisboa: Dissertação, Instituto Superior de Estudos Ultramarinos (ISEU).

PITCHER, M. Anne. 1995. "From coercion to incentives: the Portuguese colonial cotton regime in Angola and Mozambique, 1946-1974". In: Allen Isaacman \& Richard Roberts (orgs.). Cotton, colonialism and social history in Sub-Saharan Africa. Portsmouth: Heinemann. pp. 119-143.

RODRÍGUEZ-PIÑERO, Luis. 2005. Indigenous peoples, postcolonialism, and international law — the ILO Regime (1919-1989). Oxford: Oxford University Press.

SANTA RITA, José Gonçalo. 1946. "Cultura colonial”. In: Anuário da Escola Superior Colonial — ano XXVII, 1945-1946. Lisboa: Escola Superior Colonial, pp. 89-91.

SCOTT, David. 1998. Seeing like a State: how certain schemes to improve the human condition have failed. New Haven; London: Yale University Press.

SILVA, Carlos Baptista da. 2008. Administrando o império: o Ministério das Colônias/ Ultramar (1930/1974). Lisboa: Faculdade de Ciências Sociais e Humanas da Universidade Nova de Lisboa.

SILVA CUNHA, Joaquim Moreira. 1957. "Universalismo e regionalismo em África”. In: Colóquios de Politica Internacional — Estudos de Ciências Políticas e Sociais, III. Lisboa: Junta de Investigações do Ultramar, Centro de Estudos Políticos e Sociais.

SOARES, Amadeu Castilho. 1961. Politica de bem-estar rural em Angola. Lisboa: Junta de Investigaçóes do Ultramar, Centro de Estudos Políticos e Sociais.

SOUZA LIMA, Antonio Carlos de. 2002. "Sobre gestar e gerir a desigualdade: pontos de investigação e diálogo". In: (org.) Gestar e gerir: estudos para uma antropologia da administração pública no Brasil. Rio de Janeiro: Relume Dumará, pp. 11-22. 
SOUZA LIMA, Antonio Carlos de. 2005. "Os relatórios antropológicos de identificação de terras indígenas da Fundação Nacional do Índio: notas para o estudo da relação entre antropologia e indigenismo no Brasil, 1968-1985”. In: Antonio Carlos de Souza Lima \& Henyo Trindade Barreto Filho (orgs). Antropologia e identificação: os antropólogos e a definição de terras no Brasil, 1977-2002. Rio de Janeiro: ContraCapa/FAPERJ/CNPq/ LACED/IIEB. pp. 75-118.

STOLER, Ann Laura. 2009. Along the archival grain: epistemic anxieties and colonial common sense. Princeton, Oxford: Princeton University Press.

THOMAS, Nicholas. 1994. Colonialism's culture: antropology, travel and governement. Princeton: Princeton University Press.

VALENTE, Vasco Pulido. 1999. Portugal - Ensaios de História e de Política. Lisboa: Aletheia Editores

VIANNA, Adriana. 2014. "Etnografando documentos: uma antropóloga em meio a processos judiciais”. In: Sergio Castilho, Antonio Carlos de Souza Lima \& Claudia Costa Teixeira (orgs.). Antropologias das práticas de poder: reflexóes etnográficas entre burocratas, elites e corporaçôes. Rio de Janeiro: ContraCapa/FAPERJ, pp. 43-70.

WOLF, Eric. 2003. Antropologia e poder. Brasília: Editora da Universidade de Brasília; São Paulo: Imprensa Oficial do Estado de São Paulo/Editora Unicamp. 


\section{Resumo}

$\mathrm{O}$ presente artigo analisa discursos e agências que sustentaram o processo de dominação colonial em Angola nos anos 1950 tomando como base o saber colonial. Situando-o como prática discursiva, esse saber será vislumbrado com base em narrativas originadas em uma formação especializada oferecida em Lisboa para profissionais da gestấo colonial. Da descrição e análise antropológica dos trabalhos finais de alunos, localizam-se estratégias discursivas que i) tomaram os africanos como trabalhadores que não correspondiam a um ideal, ii) ampliaram classificaçóes sociais consideradas um "problema" para a administração, para além da "questão indígena" e iii) compartilharam um Estado imaginado em uma relação de dependência e, portanto, responsável pela administração de populações merecedoras de seus cuidados. Percorrem-se os lugares sociais dos textos escritos no ensino superior de administração colonial para uma compreensão das configurações sociais envolvidas no desenvolvimento de saberes administrativos projetados para territórioslongínquos nadécadade 1950. Com esse microuniverso, delineiam-se as bases para diferenciaçóes entre "nós" e "eles", os seus efeitos assimiladores e homogeneizadores, e os pressupostos e condiçóes de possibilidade para o exercício de uma vocação imperial.
In this article I analyse discourses and agencies that supported colonial domination in Angola in the 1950s, taking colonial knowledge as a basis. Situated here as a discursive practice, this knowledge emerges through the narratives originating from the specialized training offered to prospective colonial administration officers in Lisbon. An anthropological description and analysis of the final course monographs of the students enables the localization of discursive strategies that: (i) took Africans to be workers who failed to match an ideal type, (ii) widened social classifications deemed a 'problem' for the administration beyond the 'indigenous question,' and (iii) shared an idea of the State imagined through a relationship of dependency and, therefore, responsible for the administration of populations deserving of its attention. The article explores the social roles of written texts in the higher education system of the colonial administration in order to comprehend the social configurations involved in the development of administrative knowledge intended for use in distant territories in the 1950s. Through an exploration of this microuniverse, the text maps out the bases for differentiations between 'us' and 'them,' their assimilative and homogenizing effects, and the premises and conditions of possibility for exercising an imperial vocation.

Palavras-chave: saber colonial; Keywords: colonial knowledge; ciência; ensino superior; administração science; higher education; colonial colonial; Angola. administration; Angola. 